\title{
НАКОПЛЕНИЕ ТЯЖЕЛЫХ МЕТАЛЛОВ У НЕКОТОРЫХ ВИДОВ РОДА БУЗИНА В УСЛОВИЯХ ЮГО-ЗАПАДА ЦЕНТРАЛЬНОГО ЧЕРНОЗЕМЬЯ
}

\author{
V.N. Sorokopudov, M.V. Evtuhova, Yu.Yu. Ivanova, \\ S.V. Kalugina, N.S. Kukharuk
}

\section{ACCUMULATION OF HEAVY METALS IN SOME SPECIES OF THE GENUS SAMBUCUS L. IN THE SOUTH-WEST OF THE CENTRAL CHERNOZEM REGION}

Сорокопудов Владимир Николаевич - д-р с.-х. наук, проф. каф. декоративного садоводства и газоноведения Российского государственного аграрного университета - МСХА им. К.А. Тимирязева, г. Москва.

E-mail: sorokopud2301@mail.ru

Евтухова Марина Васильевна - канд. биол. наук, начальник управления ландшафтных работ и обслуживания территорий Белгородского государственного национального исследовательского университета, г. Белгород.

E-mail: Evtuhova@bsu.edu.ru

Иванова Юлия Юрьевна - канд. биол. наук, зам. начальника управления ландшастных работ и обслуживания территорий Белгородского государственного национального исследовательского университета, г. Белгород.

E-mail: Yuivanova@bsu.edu.ru

Калугина Светлана Викторовна - канд. биол. наук, доц. каф. природопользования и земельного кадастра Института наук о Земле Белгородского государственного национального исследовательского университета, г. Белгород.

E-mail: Kalugina_S@bsu.edu.ru

Кухарук Наталья Степановна - канд. биол. наук, доц. каф. природопользования и земельного кадастра Института наук о Земле Белгородского государственного национального исследовательского университета, г. Белгород.

E-mail: Kuharuk@bsu.edu.ru

Цель исследования - мониторинг тяжелых металлов в растениях видов рода бузина. Задача исследования - выявление концентраций тяжельх металлов в плодах и листьях видов бузины. Наличие и концентрация тяжелых металлов варьирует в зависимости от видов бузины и частей растений. Повышенное со-
Sorokopudov Vladimir Nikolaevich - Dr. Agr. Sci., Prof., Head, Center of Genetics, Selection and Introduction of Garden Cultures, All-Russia Selection-Technological Institute of Horticulture and Nursery, Moscow.

E-mail: sorokopud2301@mail.ru

Evtukhova Marina Vasilyevna - Cand. Biol. Sci., Head, Department of Landscape Works and Service of Territories, Belgorod State National Research University, Belgorod.

E-mail: Evtuhova@bsu.edu.ru

Ivanova Yulia Yuryevna - Cand. Biol. Sci., Deputy Head, Department of Landscape Works and Service of Territories, Belgorod State National Research University, Belgorod.

E-mail: Yuivanova@bsu.edu.ru

Kalugina Svetlana Victorovna - Cand. Biol. Sci., Assoc. Prof., Chair of Environmental Management and Land Registry, Institute of Earth Sciences, Belgorod State National Research University, Belgorod.

E-mail: Kalugina_S@bsu.edu.ru

Kukharuk Natalya Stepanovna - Cand. Biol. Sci., Assoc. Prof., Chair of Environmental Management and Land Registry, Institute of Earth Sciences, Belgorod State National Research University, Belgorod. E-mail: Kuharuk@bsu.edu.ru

держание магния - у красноплодных видов (бузина красная Плюмоза Аурея, бузина сибирская, бузина, бузина красная Плюмоза, бузина корейская), причем его концентрация в плодах выше, чем в листьях - бузина сибирская (в 2 и 1,5 раза), при этом черноплодные виды (бузина черная, бузина канадская, бузина канадская фр. 
рассеченнолистная) имеют меньшую концентрацию магния. Концентрация меди в плодах и листьях превьшает норму. В плодах в 7 (бузина красная Плюмоза Аурея) - 10 раз (бузина канадская фо. рассеченнолистная), в листьях в 2,5 (бузина корейская) - 6 раз (Бузина красная Плюмоза). Более интенсивно накапливают медь и алюминий черноплодные виды. Наuбольшие концентрации вышеуказанных металлов в плодах, меньшие - в листьях. Наибольшее отклонение от нормы данного элемента отмечено в плодах и листьях бузины красной Плюмоза - в 12 и 8 раз, а наименьшее - бузины канадской - в 8 и 3 раза. Максимальное превышение нормы свинца в плодах выявлено у бузины корейской и бузины красной - 82 раза, а в листьях - у бузины канадской фр. рассеченнолистная (2/3 от нормы). Превышение концентрации цинка в плодах и листьях бузины сибирской в 2 и 1,25 раза соотвтственно. Концентрация кобальта, никеля и стронция не имеет отклонений от нормы и колеблется от 1 до 46 \% в плодах и от 1 до 49 \% в листьях.

Ключевые слова: бузина черная (Sambucus nigra L.), бузина канадская (Sambucus canadensis L.), бузина красная Плюмоза Аурея (Sambucus racemosa Aurea L.), бузина красная (Sambucus racemosa L.), бузина красная Плюмоза (Sambucus racemosa Plumosa L.), бузина сибирская (Sambucus sibirica Nakai.), бузина канадская ф. рассеченнолистная (Sambucus canadensis Plumosa L.), бузина корейская (Sambucus coreana Nakai.), тяжелье металлы, плоды, листья.

The purpose of the research in this paper was to monitor heavy metals in plants of species of the genus elderberry. The identification of real concentrations of heavy metals in the fruits and leaves of the elderberry species is the research objective under study. The presence and concentration of heavy metals varies with elderberry species and parts of plant. Increased magnesium content was in red-fruited (Sambucus racemosa 'Aurea' L., Sambucus sibirica Nakai., Sambucus racemosa L., Sambucus racemosa 'Plumosa' L., Sambucus coreana Nakai.), and its concentration in fruits was much higher than in the leaves - Sambucus sibirica Nakai. (2 and 1.5 times, respectively). Besides, black-fruited elderberry species (Sambucus nigra L., Sambucus canadensis L., Sambucus canadensis Plumosa L.) have a lower concentration of magnesium. The concentration of copper in fruits and leaves of elderberry species is many times higher than normal. Its content in fruits 7 times (Sambucus racemosa Aurea L.) - 10 times (Sambucus canadensis Plumosa L.) and in leaves 2.5 times (Sambucus coreana Nakai) - 6 times (Sambucus racemosa Plumosa L.). More intensively accumulate copper and aluminum in various parts of plants chernoplodnye species. The highest concentrations of the above metals in the fruit, lower-in the leaves. The largest deviation from the norm of this element was observed in the fruits and leaves of Sambucus canadensis Plumosa L. - 12 and 8 times, respectively, and the smallest in Sambucus coreana Nakai. -8 and 3 times, respectively. The maximum excess of the norm of lead in fruits was found in Sambucus coreana Nakai. and Sambucus racemosa L. - almost 2 times, and in the leaves-in the species Sambucus canadensis Plumosa L. (2/3 of the norm). Excessive zinc concentration in elderberry fruits and leaves of elderberry - Sambucus sibirica Nakai.in 2 and 1.25 times, respectively). The concentration of cobalt, nickel and strontium has not deviations from the norm and ranges from 1 to $46 \%$ in fruits and from 1 to $49 \%$ in leaves.

Keyword: Sambucus nigra L., Sambucus canadensis L., Sambucus racemosa Aurea L., Sambucus racemosa L., Sambucus racemosa Plumosa L., Sambucus sibirica Nakai., Sambucus canadensis Plumosa L., Sambucus coreana Nakai., heavy metals, fruits, leaves.

Введение. В настоящее время для более объективного понимания состояния окружающей среды проводятся комплексные изучения действия экологических факторов на воздушную, водную и минеральную оболочки Земли, а также на растительный и животный мир. Именно живые организмы являются индикаторами степени негативного воздействия и указывают на необходимость принятия срочных мероприятий по обезвреживанию или прекращению действия фактора. Такие меры в первую очередь необходимо принимать на урбанизированных территориях, так как они испытывают большую антропогенную нагрузку. В городах происходит накопление поллютантов. Отсюда и следует первостепенная задача мониторинга и сохранения растений в урбанизированной среде. Растительные организмы поглощают и накапливают токсические вещества в организме, однако при этом вы- 
полняют оздоравливающее действие на окружающую среду [2]. Поэтому растительные организмы часто используют в качестве биоиндикаторов экологического состояния сред. Это основано на способности растительных организмов абсорбировать из окружающей среды практически большое количество химических элементов. Одними из самых опасных элементов выступают тяжелые металлы, особенно медь, никель.

При проведении исследований влияния загрязняющих веществ на растения необходимо помнить, что для правильного функционирования растений именно токсичная концентрация тяжелых элементов имеет большое значение [1]. Причем эти элементы могут мигрировать в организм растений корневым и фолиарным путями [3]. Анализируя информацию о распределении тяжелых металлов по органам растений, некоторые исследователи указывают на большую аккумуляцию их в подземных органах $[10,12]$, другие - в разных надземных органах (листьях, стеблях, плодах). Причинами такого распределения могут выступать видоспецифичность метаболизма организма, свойства химических элементов, которые накапливаются [11]. За эталонные значения содержания тяжелых металлов, которые не способствуют осуществлению нормальной регуляции фуункций у растений, принимаются предельно допустимые концентрации.

Цель исследования: мониторинг тяжелых металлов в растениях видов рода бузина.

Задача исследования - выявить содержание тяжелых металлов в морфологических частях исследуемых видов растений (плодах и листьях).

В настоящее время возникла острая необходимость изучения и выявления отклонений концентраций тяжелых металлов в плодах и листьях. Это объясняется неблагоприятной экологической обстановкой в районах города Белгорода. Показатели экологического состояния окружающей среды отражаются в качестве функционирования морфологических систем растительных организмов.

Состояние атмосферного воздуха является важнейшим экологическим фактором окружающей среды, и его качество зависит от выбросов загрязняющих веществ в атмоссреру предприятиями и автомобильным транспортом. Наблюдения за качеством атмосферного воздуха в городе Белгороде проводятся на четырех стационарных постах наблюдения Белгородским центром по гидрометеорологии и мониторингу окружающей среды - фрилиалом ФГБУ «Центрально-черноземное управление по гидрометеорологии и мониторингу окружающей среды». Отбор и анализ проб атмосферного воздуха показывает, что в районах города отмечается неблагоприятная экологическая обстановка. Основными источниками загрязнения атмосферы в г. Белгороде являются промышленные объекты, автомобильный и железнодорожный транспорт. Предприятия расположены в основном в западном и восточном районах города [7].

Методы и объекты исследований. Полевой эксперимент проводился в трехлетний период на растениях видов рода бузина на территории Ботанического сада Белгородского государственного национального исследовательского университета.

Концентрации тяжелых металлов в морфологических частях растений бузины (в плодах, листьях) определялись в лаборатории ФГБУ «ЦАС "Белгородский"» методом атомной спектрометрии. При этом содержание тяжелых металлов, таких как свинец и кадмий, измерялось спектрофотометром «Квант-2АТ» (ГОСТ 3017896); медь и цинк - эмиссионным спектрометром (ГОСТ 30178-96); мышьяк - фотоколориметром КФК-3-01 «3ОМЗ» (ГОСТ 26930-86), ртуть определялась анализатором ртути «Юлия-2» (ГОСТ 26927-86). Для обработки полученных данных использовали компьютерные программы: Nirsmain, Statistica 6.0, Microsoft Office Exel 2007 и руководства Б.А. Доспехова, Г.Н. Зайцева $[8,9]$.

Объектами исследований выступали плоды и листья следующих видов бузины: бузина корейская, бузина канадская, бузина красная Плюмоза Аурея, бузина красная, бузина красная Плюмоза, бузина сибирская, бузина черная, бузина канадская ф. рассеченнолистная. Плоды отбирали в период полного созревания, а листья - в период полной сформированности листовой пластины. Лабораторные исследования тяжелых металлов производили на основе водной вытяжки плодов и листьев. Эти опыты проводили на фотоколориметре КФК-2 и атомно-абсорбционном спектрофотометре (ASS-1N). Полученные данные были сопоставлены с ПДК [4-6].

Результаты исследования. Были получены результаты - в плодах (табл. 1) и в листьях (табл. 2) по следующим элементам: $\mathrm{Mn}, \mathrm{Cu}, \mathrm{Al}$, $\mathrm{Pb}, \mathrm{Zn}, \mathrm{Co}, \mathrm{Ni}, \mathrm{Sr}$. 


\section{Содержание тяжелых металлов и Al в плодах у некоторых видов рода Sambucus L.}

Таблица 1

\begin{tabular}{|c|c|c|c|c|c|c|c|c|c|c|}
\hline \multirow{3}{*}{ Вид } & \multicolumn{10}{|c|}{ Концентрация элементов тяжелых металлов и Al } \\
\hline & \multicolumn{2}{|c|}{$\mathrm{Mn}$} & \multicolumn{3}{|l|}{$\mathrm{Cu}$} & \multicolumn{3}{|c|}{$\mathrm{Al}$} & \multicolumn{2}{|l|}{$\mathrm{Pb}$} \\
\hline & мг/ת & \% от ПДК & мг/ת & \multicolumn{2}{|c|}{ \% от ПДК } & мг/ת & \multicolumn{2}{|c|}{ \% от ПДК } & $\mathrm{Mr} / \Omega$ & $\%$ от ПДК \\
\hline Бузина черная & $0.09 \pm 0.08$ & $90 \pm 79$ & \begin{tabular}{|l|l|}
$7.4 \pm 6.14$ & 7 \\
\end{tabular} & \multicolumn{2}{|c|}{$737 \pm 614$} & $5.1 \pm 3.32$ & \multicolumn{2}{|c|}{$1020 \pm 663$} & $0.05 \pm 0.035$ & $166 \pm 116$ \\
\hline $\begin{array}{l}\text { Бузина канадская ф. } \\
\text { рассеченнолистная }\end{array}$ & $0.07 \pm 0.07$ & $72 \pm 70$ & $9.7 \pm 8.159$ & \multicolumn{2}{|c|}{$970 \pm 815$} & $6.1 \pm 3.65$ & \multicolumn{2}{|c|}{$1220 \pm 730$} & $0.05 \pm 0.041 \mid 1$ & $172 \pm 136$ \\
\hline Бузина канадская & $0.07 \pm 0.07$ & $72 \pm 70$ & \begin{tabular}{|l|l|l}
$7.6 \pm 6.51$ & 7 \\
\end{tabular} & \multicolumn{2}{|c|}{$760 \pm 651$} & $5.7 \pm 3.23$ & \multicolumn{2}{|c|}{$1133 \pm 646$} & $0.05 \pm 0.043$ & $169 \pm 144$ \\
\hline Бузина корейская & $0.11 \pm 0.10$ & $110 \pm 96$ & $8.9 \pm 7.718$ & \multicolumn{2}{|c|}{$891 \pm 771$} & $4.0 \pm 3.11$ & \multicolumn{2}{|c|}{$807 \pm 623$} & \begin{tabular}{|l|l|}
$0.05 \pm 0.048$ & 1 \\
\end{tabular} & $181 \pm 159$ \\
\hline \begin{tabular}{|} 
Бузина красная Плюмоза \\
Ауреа
\end{tabular} & $0.11 \pm 0.10$ & $110 \pm 96$ & $7.2 \pm 5.41$ & \multicolumn{2}{|c|}{$720 \pm 541$} & $4.8 \pm 3.81$ & \multicolumn{2}{|c|}{$961 \pm 762$} & $0.03 \pm 0.025$ & $97 \pm 84$ \\
\hline Бузина красная Плюмоза & $0.11 \pm 0.10$ & $107 \pm 93$ & \begin{tabular}{|l|l|}
$7.7 \pm 7.00$ & 7 \\
\end{tabular} & \multicolumn{2}{|c|}{$774 \pm 704$} & $5.2 \pm 4$ & \multicolumn{2}{|c|}{$1045 \pm 800$} & $0.03 \pm 0.024$ & $93 \pm 81$ \\
\hline Бузина сибирская & $20 \pm 0.18$ & $197 \pm 18$ & \begin{tabular}{|l|l|}
$8.6 \pm 5.47$ & 8 \\
\end{tabular} & \multicolumn{2}{|c|}{$855 \pm 547$} & $4.2 \pm 3.37$ & \multicolumn{2}{|c|}{$844 \pm 675$} & \begin{tabular}{|l|l|}
$0.03 \pm 0.030$ & 1 \\
\end{tabular} & $112 \pm 100$ \\
\hline Бузина к & $0.10 \pm 0.09$ & $100 \pm 87$ & \begin{tabular}{|l|l|}
$7.9 \pm 7.08$ & 7 \\
\end{tabular} & \multicolumn{2}{|c|}{$795 \pm 708$} & $5.2 \pm 4.14$ & \multicolumn{2}{|c|}{$1043 \pm 827$} & $0.05 \pm 0.047$ & $180 \pm 156$ \\
\hline ПДК в воде & 0.1 & 100 & 1 & \multicolumn{2}{|c|}{100} & 0.5 & \multicolumn{2}{|c|}{100} & 0.03 & 100 \\
\hline \multirow{3}{*}{ Вид } & \multicolumn{10}{|c|}{ Концентрация элементов тяжелых металлов } \\
\hline & \multicolumn{2}{|c|}{$\mathrm{Zn}$} & \multicolumn{3}{|l|}{ Co } & \multicolumn{3}{|c|}{$\mathrm{Ni}$} & \multicolumn{2}{|l|}{$\mathrm{Sr}$} \\
\hline & мг./л & \% от ПДК & мг/л. & & $\begin{array}{l}\% \text { от } \\
\text { ПДК }\end{array}$ & $\mathrm{Mr} / \Omega$ & & $\begin{array}{l}\text { \% от } \\
\text { ПДК }\end{array}$ & мг/л & $\begin{array}{l}\text { \% от } \\
\text { ПДК }\end{array}$ \\
\hline Бузина черная & $0.22 \pm 0,19$ & $22 \pm 19$ & $0.016 \pm 0.00$ & & $6 \pm 4$ & $0.017 \pm 0.0$ & & $17 \pm 12$ & $0.073 \pm 0.038$ & \begin{tabular}{|l|l|}
3 & $1.0 \pm 1.0$ \\
\end{tabular} \\
\hline $\begin{array}{l}\text { Бузина канадская ф. } \\
\text { рассеченнолистная }\end{array}$ & $0.29 \pm 0,24$ & $29 \pm 24$ & \pm 0.00 & & $16 \pm 8$ & 0. & & $20 \pm 11$ & $3 \pm 0.038$ & $1.2 \pm 0.5 \mid$ \\
\hline Бузина канадская & $0.23 \pm 0,15$ & $23 \pm 15$ & $0.016 \pm 0.00$ & & $16 \pm 8$ & $0.021 \pm 0.0$ & & $21 \pm 11$ & $0.093 \pm 0.029$ & $1.4 \pm 0.4$ \\
\hline Бузина корейская & $0.17 \pm 0,10$ & $17 \pm 10$ & $0.013 \pm 0.01$ & & $\begin{array}{c}13 \pm \\
13 \\
\end{array}$ & $0.013 \pm 0.0$ & & $13 \pm 11$ & $0.115 \pm 0.079$ & $\mid 1.6 \pm 1.1$ \\
\hline Бузина сибирская & $2.00 \pm 3,08$ & $200 \pm 308$ & $0.013 \pm 0.01$ & & $\begin{array}{c}13 \pm \\
13 \\
\end{array}$ & $0.046 \pm 0.0$ & & $46 \pm 65$ & $0.103 \pm 0.031$ & $1.5 \pm 0.5$ \\
\hline \begin{tabular}{|l|} 
Бузина красная \\
Плюмоза Ауреа \\
\end{tabular} & $0.28 \pm 0,06$ & $28 \pm 6$ & $0.013 \pm 0.01$ & & $\begin{array}{c}13 \pm \\
15 \\
\end{array}$ & $0.011 \pm 0.0$ & & $11 \pm 9$ & 0.12 & $=2.0$ \\
\hline Бузина красная & $0.28 \pm 0,20$ & $28 \pm 20$ & $0,013 \pm 0.01$ & & $\begin{array}{c}13 \pm \\
13 \\
\end{array}$ & $0.009 \pm 0.0$ & & $9 \pm 9$ & $0.114 \pm 0.081$ & $1.6 \pm 1.1$ \\
\hline $\begin{array}{l}\text { Бузина красная } \\
\text { Плюмоза }\end{array}$ & $0.37 \pm 0,15$ & $37 \pm 15$ & $0.013 \pm 0.01$ & & $\begin{array}{c}13 \pm \\
13 \\
\end{array}$ & $0.012 \pm 0.0$ & & $12 \pm 11$ & $0.124 \pm 0.089$ & $1.8 \pm 1.3$ \\
\hline ПДК в & 1 & 100 & 0.1 & & 100 & 0.1 & & 100 & 7 & 100 \\
\hline
\end{tabular}

Содержание тяжелых металлов и Al в листьях у некоторых видов рода Sambucus $L$.

Таблица 2

\begin{tabular}{|c|c|c|c|c|c|c|c|c|}
\hline \multirow{3}{*}{ Вид } & \multicolumn{8}{|c|}{ Концентрация элементов тяжелых металлов и Al } \\
\hline & \multicolumn{2}{|c|}{$\mathrm{Mn}$} & \multicolumn{2}{|c|}{$\mathrm{Cu}$} & \multicolumn{2}{|c|}{$\mathrm{Al}$} & \multicolumn{2}{|c|}{$\mathrm{Pb}$} \\
\hline & $\mathrm{Mr} / \Omega$ & \% от ПДК & $\mathrm{Mr} / \Omega$ & \% от ПДК & $\mathrm{Mr} / \pi$ & $\%$ от ПДК & $\mathrm{Mr} / \pi$ & $\%$ от ПДК \\
\hline 1 & 2 & 3 & 4 & 5 & 6 & 7 & 8 & 9 \\
\hline Бузина черная & $0.07 \pm 0.06$ & $68 \pm 62$ & $4.15 \pm 3.5$ & $415 \pm 350$ & $\begin{array}{c}2.96 \pm \\
2.02\end{array}$ & $591 \pm 403$ & $0.05 \pm 0.04$ & $157 \pm 132$ \\
\hline $\begin{array}{l}\text { Бузина канадская ф. } \\
\text { рассеченнолистная }\end{array}$ & $0.05 \pm 0.05$ & $52 \pm 50$ & $\begin{array}{c}4.89 \pm \\
4.14 \\
\end{array}$ & $489 \pm 414$ & $\begin{array}{c}3.84 \pm \\
2.64 \\
\end{array}$ & $769 \pm 527$ & $0.05 \pm 0.04$ & $169 \pm 146$ \\
\hline Бузина канадская & $0.05 \pm 0.05$ & $52 \pm 50$ & $\begin{array}{c}4.69 \pm \\
4.03\end{array}$ & $469 \pm 403$ & $\begin{array}{c}3.17 \pm \\
1.74\end{array}$ & $633 \pm 348$ & $0.05 \pm 0.04$ & $158 \pm 140$ \\
\hline Бузина корейская & $0.11 \pm 0.10$ & $113 \pm 98$ & $\begin{array}{c}2.47 \pm \\
3.84 \\
\end{array}$ & $247 \pm 384$ & $\begin{array}{c}1.65 \pm \\
1.72\end{array}$ & $331 \pm 343$ & $0.04 \pm 0.04$ & $140 \pm 142$ \\
\hline Бузина сибирская & $0.14 \pm 0.12$ & $137 \pm 123$ & $\begin{array}{c}4.77 \pm \\
2.83 \\
\end{array}$ & $477 \pm 283$ & $\begin{array}{c}3.22 \pm \\
3.07 \\
\end{array}$ & $645 \pm 614$ & $0.04 \pm 0.05$ & $130 \pm 154$ \\
\hline $\begin{array}{l}\text { Бузина красная } \\
\text { Плюмоза Ауреа }\end{array}$ & $0.10 \pm 0.08$ & $97 \pm 84$ & $\begin{array}{c}3.57 \pm \\
3.06\end{array}$ & $357 \pm 306$ & $\begin{array}{c}1.80 \pm \\
1.61 \\
\end{array}$ & $359 \pm 323$ & $0.03 \pm 0.04$ & $110 \pm 126$ \\
\hline
\end{tabular}


Окончание табл. 2

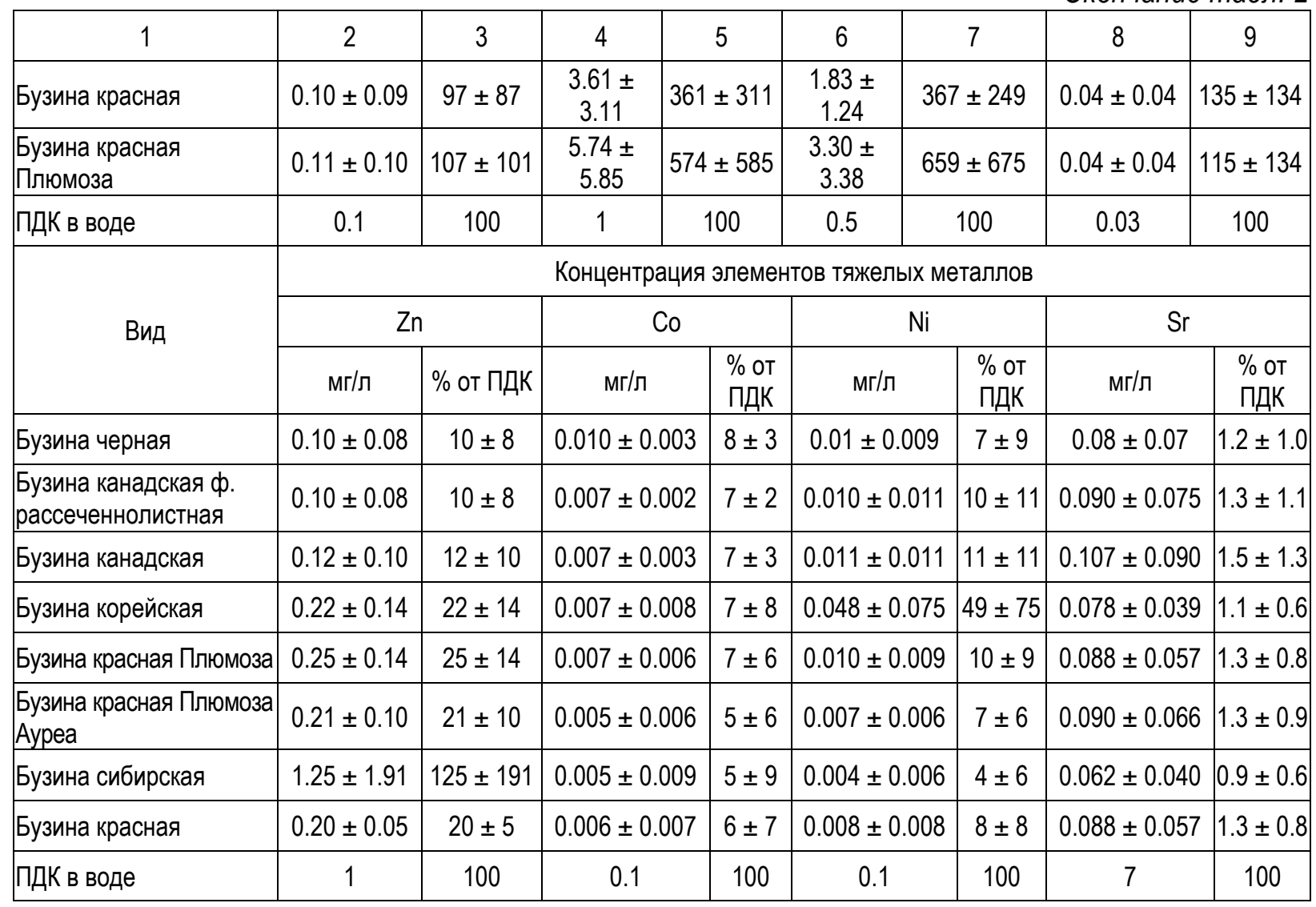

Виды бузины различаются степенью накопления тяжелых металлов в частях растений. У всех видов бузины происходит накопление повышенного содержания марганца. Это выявлено у всех исследуемых видовых растений, но особенно проявляется у красноплодных (бузина красная Плюмоза, бузина сибирская, бузина обыкновенная, бузина красная Плюмоза Ауреа, бузина корейская). При этом концентрация марганца в плодах выше, чем в листьях. Наибольшее отклонение концентрации марганца от нормы выявлено в плодах бузины сибирской в 2 раза, а в листьях - в 1,5. Виды бузины черной, бузины канадской, бузины канадской ф. рассеченнолистная имеют меньшее содержание марганца в плодах и листьях, однако его показатели близки к пороговым значениям предельно допустимых концентраций.

При проведении исследований содержания такого тяжелого металла, как медь, установлено, что значения меди превышают показания ПДК у всех видов бузины в исследуемых морфологических частях растений: в плодах в 7 (бузина красная Плюмоза Ауреа) - 10 раз (бузина канадская Плюмоза), в листьях в 2,5 (бузина корейская) - 6 раз (бузина красная Плюмоза). Отмечено, что более интенсивно накапливают медь черноплодные виды. При этом накопление идет в различных частях растений, что объясняется их биологическими особенностями.

Содержание алюминия характеризуется наибольшими отклонениями от нормы. Этот элемент имеет самые высокие показатели отклонения от предельно допустимых концентраций. Максимальные его показатели отмечены в плодах, наименьшие - в листьях. Выявлено, что более интенсивно алюминий накапливают растения рода Sambucus (черноплодные виды). Максимальное отклонение концентрации от ПДК алюминия отмечено в плодах Sambucus canadensis Plumosa L. в 12 раз, в листьях - в 8, а минимальное в плодах Sambucus coreana Nakai - в 8 раз, в листьях - в 3.

При проведении лабораторных исследований концентраций свинца в плодах и листьях разных видов бузины выявлено, что предельно допустимые концентрации значений слабо превышены по сравнению с другими показателями содержания тяжелых металлов. Максимальные значения свинца в плодах выявлены у 
Sambucus coreana Nakai и Sambucus racemosa L. - в 2 раза превышение ПДК, в листьях у Sambucus canadensis Plumosa L. отклонение на 2/3 от нормы.

Исследование концентрации такого тяжелого металла, как цинк, в плодах и листьях разных видов бузины не превышает ПДК по данному показателю в растениях. Однако у одного вида Sambucus sibirica Nakai наблюдается превышение ПДК. Это вид рода бузины отличается большей способностью к накоплению данного поллютанта в морфологических частях растения (плодах и листьях). В проведенных исследованиях отмечено превышение концентраций в плодах в 2 раза, в листьях - в 1,25 раза.

Исследование содержания тяжелых металлов, таких как кобальт, никель и стронций, в растениях показало, что их концентрация не имеет отклонений от нормы. Показания содержания кобальта, никеля, стронция колеблятся у разных видов рода бузина от 1 до $49 \%$ в листьях и от 1 до 46 \% в плодах по сравнению с ПДК.

\section{Выводы}

1. Комплекс проведенных исследований по выявлению концентраций тяжелых металлов в плодах и листьях отдельных видов бузины, произрастающих в условиях юго-запада Центрального Черноземья показал, что концентрации тяжелых металлов - марганца, меди и цинка и не тяжелого металла алюминия у большей части изученных видов рода Sambucus L. превышают предельно допустимые значения.

2. Незначительные превышения предельно допустимых концентраций фриксируются по таким тяжелым металлам, как кобальт, никель, свинец, стронций.

3. Плоды и листья таких видов бузины, как бузина красная Плюмоза Ауреа, бузина сибирская, бузина черная, характеризующиеся поглощением и накоплением тяжелых металлов в количествах, превышающих ПДК, не могут быть рекомендованы к использованию в лечебных и пищевых целях.

4. Другие изученные виды бузины могут иметь ограниченное применение в соответствии с целью. Экологически безопасная продукция может быть получена при выращивании бузины за пределами техногенных ареалов загрязнения, выявленных на территориях исследования.

\section{Литература}

1. Биохимический состав плодов и ягод и их пригодность для переработки / Н.И. Савельев, В.Г. Леонченко, В.Н. Макаров [и др.]; Всерос. НИИ генетики и селекции плодовых растений им. И.В. Мичурина. Мичуринск: Изд-во ВНИИГиСПР, 2004. $122 \mathrm{c}$.

2. Виноградов А.П. Основные закономерности В распределении микроэлементов между растениями и средой // Микроэлементы в жизни растений и животных. М.: Наука, 1985. C. 7-20.

3. Волошин Е.И. Баланс микроэлементов и тяжелых металлов в агроценозах Красноярского края // Вестн. КрасГАУ. 2017. № 3. C. 21-28.

4. ГОСТ 26927-86. Сырье и продукты пищевые. Методы определения ртути. Введ. 1986-01-12. М.: Изд-во стандартов, 1986. $12 \mathrm{c}$.

5. ГОСТ 26930-86. Сырье и продукты пищевые. Метод определения мышьяка. Введ. 1987-01-01. М.: Изд-во стандартов, 1986. $8 \mathrm{c}$.

6. ГОСТ 30178-96. Сырье и продукты пищевые. Атомно-абсорбционный метод определения токсичных элементов. Введ. 199801-01. М.: Изд-во стандартов, 1997. 8 с.

7. Государственный доклад об экологической ситуации в Белгородской области в 2017 году. URL: https://belregion.ru/author/?ID= 124.

8. Доспехов Б.А. Методика полевого опыта: с основами статистической обработки результатов исследования: учебник. 5-е изд., доп. и перераб. М.: Агропромиздат, 1985. $351 \mathrm{c}$.

9. Зайщев Г.Н. Математический анализ биологических данных / АН СССР, Гл. ботан. сад. М.: Наука, 1991. 182 с.

10. Прохорова Н.В., Матвеев Н.М., Павловский В.А. Аккумуляция тяжелых металлов дикорастущими и культурными растениями в лесостепном и степном Поволжье. Самара, 1998. $131 \mathrm{c}$. 
11. Сорокопудов В.Н., Кольцов С.В., Волощенко Л.В. Интегральная оценка перспективности некоторых видов рода Sambucus L. при интродукции // Плодоводство и виноградарство Юга России. 2015. № 36 (6). C. 116-128.

12. Хижняк Р.М. Экологическая оценка содержания микроэлементов ( $\mathrm{Zn}, \mathrm{Cu}, \mathrm{Co}, \mathrm{Mo}, \mathrm{Cr}$, Ni) в агроэкосистемах лесостепной зоны юго-западной части ЦЦЧО: дис. ... канд. биол. наук: 03.02.08. М., 2015. 129 с.

\section{Literatura}

1. Biohimicheskij sostav plodov $\mathrm{i}$ jagod $\mathrm{i}$ ih prigodnost' dlja pererabotki / N.I. Savel'ev, V.G. Leonchenko, V.N. Makarov [i dr.]; Vseros. NII genetiki i selekcii plodovyh rastenij im. I.V. Michurina. Michurinsk: Izd-vo VNIIGiSPR, 2004. $122 \mathrm{~s}$.

2. Vinogradov A.P. Osnovnye zakonomernosti v raspredelenii mikrojelementov mezhdu rastenijami i sredoj // Mikrojelementy v zhizni rastenij i zhivotnyh. M.: Nauka, 1985. S. 7-20.

3. Voloshin E.I. Balans mikrojelementov i tjazhelyh metallov $v$ agrocenozah Krasnojarskogo kraja // Vestn. KrasGAU. 2017. № 3. S. 21-28.

4. GOST 26927-86. Syr'e i produkty pishhevye. Metody opredelenija rtuti. Vved. 1986-01-12. M.: Izd-vo standartov, 1986. $12 \mathrm{~s}$.
5. GOST 26930-86. Syr'e i produkty pishhevye. Metod opredelenija mysh'jaka. Vved. 198701-01. M.: Izd-vo standartov, 1986. - $8 \mathrm{~s}$.

6. GOST 30178-96. Syr'e i produkty pishhevye. Atomno-absorbcionnyj metod opredelenija toksichnyh jelementov. Vved. 1998-01-01. M.: Izd-vo standartov, $1997.8 \mathrm{~s}$.

7. Gosudarstvennyj doklad ob jekologicheskoj situacii v Belgorodskoj oblasti v 2017 godu. URL: https://belregion.ru/author/?ID=124.

8. Dospehov B.A. Metodika polevogo opyta: $\mathrm{s}$ osnovami statisticheskoj obrabotki rezul'tatov issledovanija: uchebnik. 5-e izd., dop. i pererab. M.: Agropromizdat, 1985. - $351 \mathrm{~s}$.

9. Zajcev G.N. Matematicheskij analiz biologicheskih dannyh / AN SSSR, GI. botan. sad. M.: Nauka, 1991. $182 \mathrm{~s}$.

10. Prohorova N.V., Matveev N.M., Pavlovskij V.A. Akkumuljacija tjazhelyh metallov dikorastushhimi i kul'turnymi rastenijami v lesostepnom i stepnom Povolzh'e. Samara, 1998. $131 \mathrm{~s}$.

11. Sorokopudov V.N., Kol'cov S.V., Voloshhenko L.V. Integral'naja ocenka perspektivnosti nekotoryh vidov roda Sambucus L. pri introdukcii // Plodovodstvo i vinogradarstvo Juga Rossii. 2015. № 36 (6). S. $116-128$.

12. Hizhnjak R.M. Jekologicheskaja ocenka soderzhanija mikrojelementov ( $\mathrm{Zn}, \mathrm{Cu}, \mathrm{Co}$, $\mathrm{Mo}, \mathrm{Cr}, \mathrm{Ni}) \mathrm{v}$ agrojekosistemah lesostepnoj zony jugo-zapadnoj chasti CChO: dis. ... kand. biol. nauk: 03.02.08. M., 2015. 129 s. 